\section{Magnitude production and magnitude estimation of taste intensity}

\author{
HERBERT L. MEISELMAN, HARRY E. BOSE \\ and WILLIAM F. NYKVIST \\ Pioneering Research Laboratory \\ U.S. Army Natick Laboratories, Natick, Massachusetts 01760
}

Magnitude productions of sodium chloride (salty), quinine hydrochloride (bitter), and sucrose (sweet) yielded steeper psychophysical functions than those obtained with magnitude estimation. Hydrochloric acid (sour) produced the opposite effect. The results are discussed with respect to previous findings in taste intensity scaling and to general psychophysical considerations.

Since 1960, there has been an increase in the use of ratio scaling techniques in the study of taste psychophysics (see Meiselman, 1971). However, the ratio scaling techniques have been entirely limited to magnitude estimation procedures. Whereas some work has been directed toward the determination of invariance within gustatory psychophysics (Moskowitz, 1970, 1971a), other work has focused on the apparent variance across experiments (Meiselman, 1971).

The magnitude production procedure involves giving control of the stimulus dimension to the $S$, who matches the stimulus level to another dimension (usually a number). In magnitude estimation procedures, S makes a numerical estimation to match the stimulus level. The magnitude production procedure has been shown to result in steeper psychophysical functions, i.e., functions with higher slopes or higher power function exponents, for the dimensions of handgrip (Stevens \& Mack, 1959; Stevens \& Guirao, 1962), loudness (Reynolds \& Stevens, 1960), and duration (Stevens \& Greenbaum, 1966). Stevens and Greenbaum (1966) have interpreted the difference between magnitude estimation and magnitude production as a regression effect, wherein $S$ tends to constrict the range of the variable dimension. They further suggest that the regression effect is unaffected or little affected by practice, or by the range of stimuli, and that a geometric mean of the two slopes might be the best estimate of the unbiased slope. Moskowitz (1971b) suggests that averaging slopes of the functions may not completely cancel the regression effect and suggests a different experimental paradigm for minimizing it. That paradigm comprises matches of the two criterion modalities (number and taste) by a third common modality, e.g., handgrip or loudness.

The present experiment was undertaken to examine the psychophysical functions produced by magnitude estimation and magnitude production procedures. Responses were obtained using magnitude estimation and magnitude production procedures from the same group of Ss for taste stimuli representing each of the traditional taste quality categories (sweet, sour, salty, bitter).

\section{METHOD}

The Ss were selected from male laboratory personnel, ages 22-27, at the U.S. Army Natick Laboratories. Each $S$ served under both magnitude estimation and magnitude production conditions. A group of 10 Ss was used for each of the four stimulus compounds. Of these, 3 served in all four groups.

All stimuli were presented through a gustometer (Fig. 1), which was constructed from glass tubing, stainless steel pins, a specially drilled three-way stopcock, and an adjusting dial with attached reduction gears. The stopcock was drilled 30 deg off center such that either of the two glass tubes could be turned on while the other was in the off position or any desired proportion of the two tubes could be turned on. The adjusting dial with its attached reduction gears was affixed to the top of the stopcock. By turning the adjusting dial in either direction, a total of six revolutions rotated the stopcock from the open position for one glass tube completely around to the open position of the second glass tube. One-way valves were placed at the end of each glass tube to insure that once a solution was in the gustometer, it would flow out of the opening at the base of the stopcock.

Concentrated solutions of sucrose, hydrochloric acid ( $\mathrm{HCl}$ ), sodium chloride ( $\mathrm{NaCl}$ ), and quinine hydrochloride (QHCl) were prepared with reagent grade chemicals and distilled $\mathrm{H}_{2} \mathrm{O}$ (refractive index = 1.3330 ). They were placed in $1 / 2-g a l$ plastic bottles and stored in a water bath at $37 \pm 1^{\circ} \mathrm{C}$ prior to an experimental session. Distilled water was placed in a second 1/2-gal plastic bottle which was also located in the water bath. During an experimental session, the pressure within the bottles was increased by $2 \mathrm{psi}$, using a portable nitrogen source and a control valve. Thus, the liquids within the bottles were forced into the gustometer through two plastic tubes attached to each of the glass tubes and the stopcock. The resulting solution was thoroughly mixed as it passed over the stainless steel pins located in the opening at the base of the stopcock.

The $\mathbf{S}$ sampled the stimulus solution by releasing a 2 -in. spring clamp located at the base of the gustometer and attached to the output of the stopcock. He extended his tongue into the stream of stimulus solution and closed his lips around the posterior portion of his tongue. This prevented the solution from entering his mouth. This anterior dorsal tongue flow procedure has been widely used (McBurney, 1966; Meiselman, 1971).

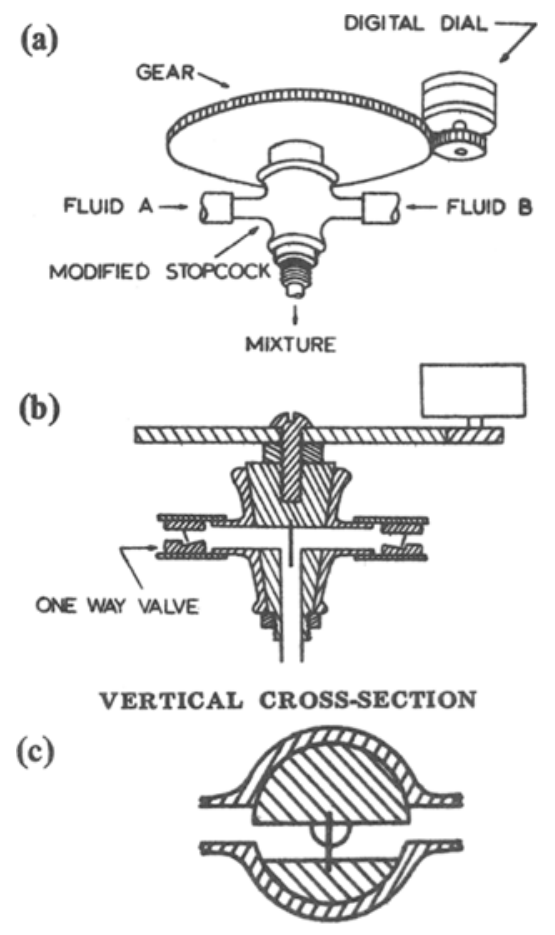

\section{HORIZONTAL CROSS-SECTION}

Fig. 1. (a) Schematic diagram of gustometer showing flow inputs for two fluids (A, B), reduction gear, and digitally calibrated dial for $S$ manipulation. (b) Vertical crossection of gustometer showing oneway valves in flow inputs and preasure baffle (heavy black line) located at meeting of two flow inputs. (c) Horizontal cross-section of stopcock and flow inputs showing placement of baffle and relationship of flow input to flow output. 

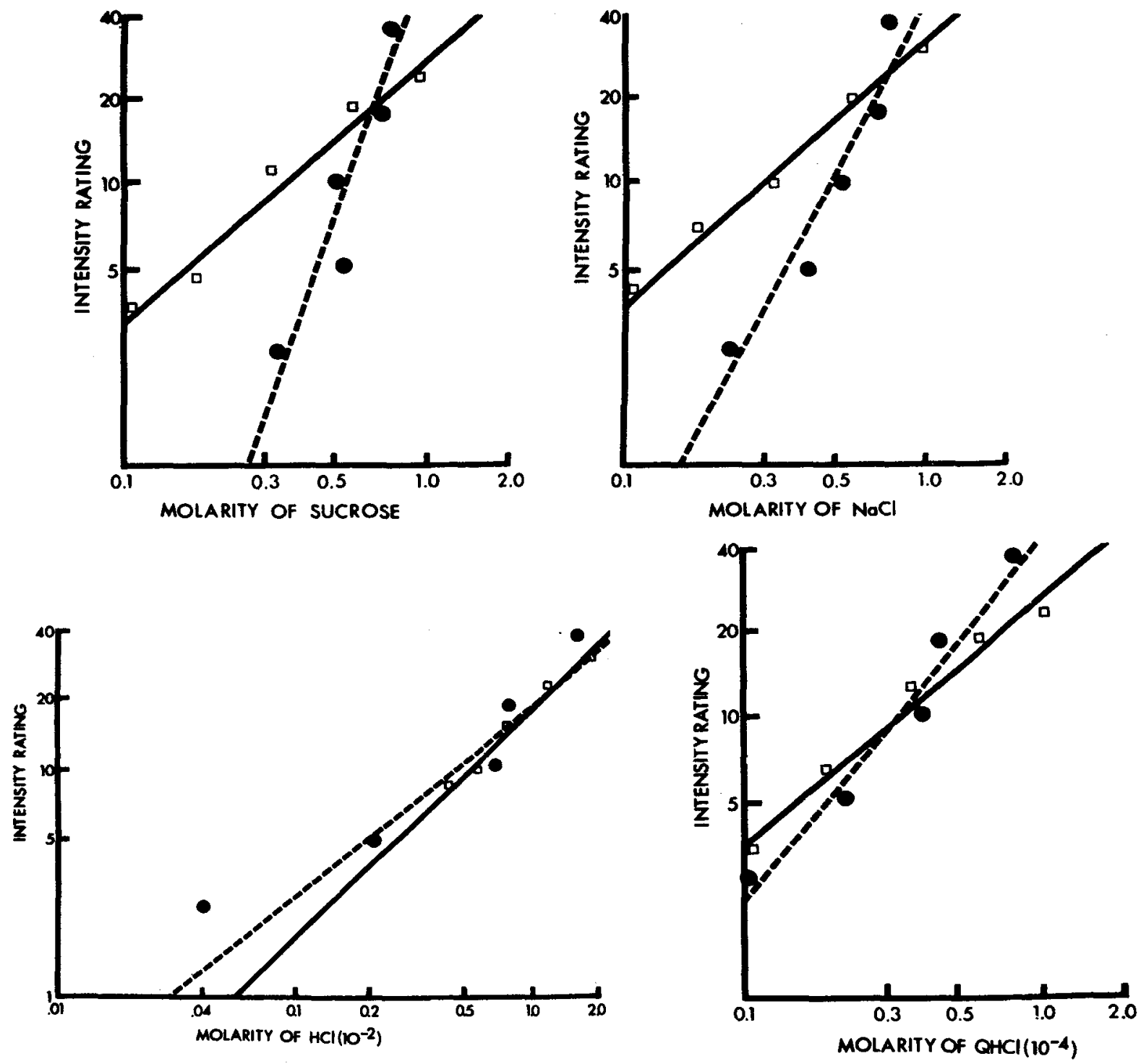

Fig. 2. Median magnitude ratings as a function of solution concentration for each stimulus compound. The solid black line (open squares) represents the magnitude estimations, and the hatched line (closed circles) represents the magnitude productions.

All stimuli were presented at a flow rate of $5 \mathrm{cc} / \mathrm{sec}$.

The concentrations of the $\mathrm{NaCl}$ and sucrose stimuli were determined by sampling the solutions as they left the gustometer and measuring their refractive indices with a precision refractometer (Bosch \& Lomb, Model 33-45-58). The refractive indices of the samples were compared with calibration curves based on the refractive indices of standard solutions prepared at this laboratory. The $\mathrm{QHCl}$ and $\mathrm{HCl}$ stimulus concentrations were determined from their conductivity, measured with a flow-through conductivity meter (Radiometer, Type CDM2D), placed in series with the output of the gustometer. The conductivities of the stimuli were compared to calibration curves based on the conductivity of standard solutions prepared at this laboratory.

For magnitude estimations, Ss were presented with a standard. The standards for $\mathrm{NaCl}$ and sucrose were $0.32 \mathrm{M}$, for $\mathrm{QHCl}, 0.32 \times 10^{-4} \mathrm{M}$, and for $\mathrm{HCl}, 0.81 \times 10^{-2} \mathrm{M}$. Ss were asked to estimate the intensity of all later solutions by using numbers in proportion to the strength of the standard according to theprocedure of magnitude estimation. Ss were instructed to judge the initial intensity of the stimuli. Two presentations of $0.1,0.18,0.32,0.60$, and $1.00 \mathrm{M}$ solutions for $\mathrm{NaCl}$ and sucrose were evaluated by each $\mathrm{S}$. For $\mathrm{QHCl}$, the concentrations were $0.1 \times 10^{-4}, 0.18$ $\times 10^{-4}, 0.32 \times 10^{-4}, 0.60 \times 10^{-4}$ and $1.00 \times 10^{-4} \mathrm{M}$; for $\mathrm{HCl}$ they were $.4 \times 10^{-2}, .57 \times 10^{-2}, 0.81 \times 10^{-2}$,

Table 1

Magnitude Estimation Exponent, Magnitude Production Exponent, and Geometric Mean for Each Stimulus Compound

\begin{tabular}{lcccc}
\hline & NaC1 & QHC1 & Sucrose & HC1 \\
\hline Magnitude Estimation Exponent & 0.91 & 0.85 & 0.93 & 0.99 \\
Magnitude Production Exponent & 2.09 & 1.28 & 2.93 & 0.70 \\
Geometric Mean & 1.37 & 1.04 & 1.62 & 0.83 \\
\hline
\end{tabular}


$1.15 \times 10^{-2}$, and $1.65 \times 10^{-2} \mathrm{M}$.

During magnitude production of all four taste stimuli, Ss were presented with the standard and then asked to adjust the gustometer such that the concentration of the stimulus was proportional to numbers given him by the E. S was instructed to adjust the gustometer by bracketing the desired stimulus intensity, i.e., obtaining the desired intensity by approaching it from above and below. Between 2 and 15 adjustments were used by $S$ for the determination of the response on the gustometer. Ss were instructed to adjust the stimulus intensity in proportion to numbers of $2.5,5,10$, 18 , and 36 , using 10 as the standard. These numbers were given twice in a random order, with a presentation of the standard between each series of numbers. $S$ reported when he thought the solutions' intensities were proportional to the number given him, and the $E$ recorded the concentration.

For the magnitude estimations of $\mathrm{NaCl}$ and sucrose, concentrations of the stimulus, as indicated above, were prepared in advance and presented to $\mathrm{S}$ through the gustometer. The $\mathrm{QHCl}$ and $\mathrm{HCl}$ solutions were prepared at the time of their presentation to $S$, using the gustometer to mix a concentrated stimulus solution and distilled water to produce the desired concentrations. The $E$ adjusted the concentration of the solution and told $S$ when to sample the stimulus. Ss rated the stimulus intensity in proportion to the standard, which had been assigned a value of 10 . During both magnitude estimation and magnitude productionprocedures, Ss rinsed their mouths by sipping distilled water from a beaker after each stimulus presentation. There was a pause of at least 15 sec between stimuli.

\section{RESULTS AND DISCUSSION}

The median rating of each $S$ at each concentration level was determined for each of the four taste stimuli. The median intensity rating was plotted against the five concentrations of each stimulus for the magnitude estimation procedure. In a like manner, the median stimulus concentration was plotted against the five different numbers used in the magnitude production procedures. Linear regression analyses (McNemar, 1962) based on the logs of each of the median concentrations for the magnitude production procedure and on the logs of the relative intensity ratings for the magnitude estimation procedure produced equations with slopes characteristic of each procedure for each stimulus. The geometric mean of each pair of slopes representing the estimation and production procedures for each stimulus was then calculated (Table 1).

Table 2

Exponents for Previously Reported Taste Functions

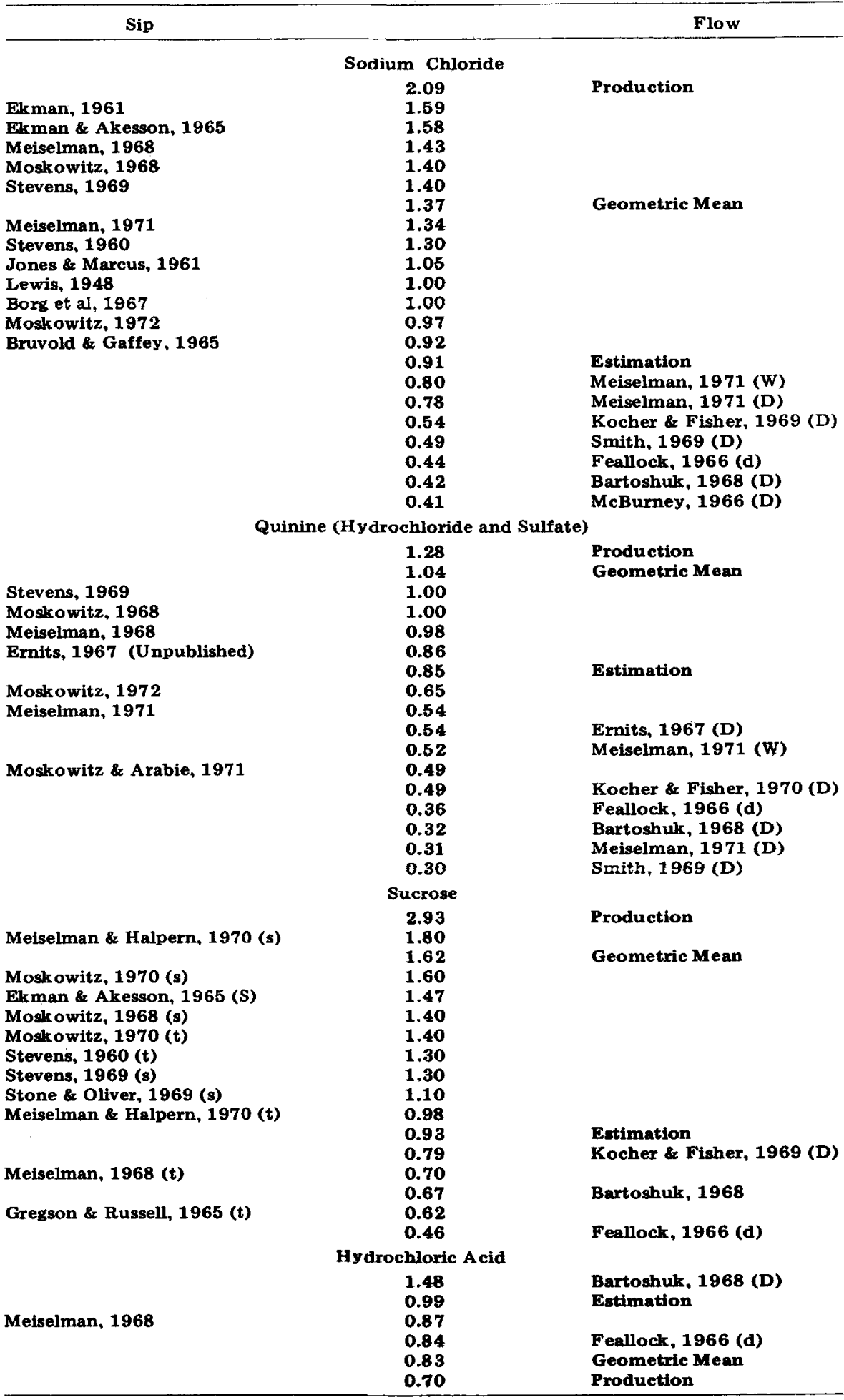

Note-Exponents are listed in order of decreasing size. Experiments cited to the left of the exponent used a sip procedure and those cited to the right used a How procedure. The flowing experiments are distinguished as follows: $D$, dorsal flow; $W$, whole mouth flow; $d$, dorsal flow to a small area. The exponents from the present study are listed according to the type of procedure as well as the geometric mean of each pair.

The magnitude production slope was higher than the magnitude estimation slope for all of the stimuli except $\mathrm{HCl}$.

Table 2, adapted from Meiselman (1971), indicates how the exponents 
calculated from the data of the present experiment compare with exponents generated in previous studies. The exponents produced by magnitude estimations of a flowing stimulus of $\mathrm{NaCl}$, sucrose, and $\mathrm{QHCl}$ fit in well with previous research findings, with a general tendency for the exponents of the present experiment to be somewhat high. For these compounds, the magnitude production exponent is noticeably larger than any previously reported exponent for group data using any procedure. Since Meiselman (1971) reported that the dorsal tongue flow procedure tended to produce flatter psychophysical functions, it is possible that the function achieved through magnitude production of a sipped stimulus would produce an even steeper function with a higher exponent.

Whereas the relatively small amount of previous research for $\mathrm{HCl}$ makes comparisons difficult, it appears that responses to the $\mathrm{HCl}$ solutions do not fit the generalizations relating either to method of stimulus presentation (flow vs sip) or to scaling task (production vs estimation). In the latter instance, the production-generated function had a smaller exponent than the estimation-generated exponent. More work is required both with $\mathrm{HCl}$ and with other sour-tasting stimuli before any conclusions can be reached regarding procedural effects on sourness.

For $\mathrm{NaCl}$, the geometric mean of the magnitude production-generated exponent and the magnitude estimation-generated exponent, both achieved with a flowing stimulus, represents a typical exponent generated with a sipped stimulus and an estimation task. The results for sucrose and QHCl are close, but not as clear as with $\mathrm{NaCl}$. The present work has shown that previously reported regression effects generally hold for gustatory stimuli and that for some stimuli, the geometric mean of estimation and production procedures possibly yields an exponent value more truly representative of the dimension.

The large variability in reported exponents for psychophysical functions of taste intensity might be distressing to those who view the exponent as the invariant around which psychophysical research can work. Indeed, in taste research, the variability of the reported exponent might provide the stimulus for research on how taste research methods contribute to this variability. Recent work has shown the effects of stimulus presentation methods (Meiselman, 1971). When taste research has properly investigated its methods and determined their effects on results, then a more standardized set of procedures can be instituted, as is the case in both vision and audition. More standardized procedures will probably result in less variable data.

More work is needed to specify gustatory functions. Specifically, magnitude production with a sipped stimulus is required to complete the combinations of procedures already reported. It might be argued that the psychophysical function determined with a sipped stimulus is the most appropriate for the modality because sipping is the normal mode of taste stimulus exposure. The possibility exists that each method of taste stimulus presentation will yield a representative psychophysical function with a different exponent.

\section{REFERENCES}

BARTOSHUK, L. M. Water taste in man. Perception \& Psychophysics, 1968,3, 69-72.

BORG, G. DIAMANT, H STROM, L., \& ZOTTERMAN, $Y$. The relation between neural and perceptual intensity: $A$ comparative study on the neural and psy chophysical response to taste stimuli. Journal of Physiology, 1967, 192, 13-20.

BRUVOLD, W. H \& GAFFEY, W. R. Subjective intensity of mineral taste in water. Journal of Experimental Psy chology, 1965, 69, 369-374.

EKMAN, G. Methodological note on scales of gustatory intensity. Scandinavian Journal of Psychology, 1961, 2, 185-190. EKMAN, G., \& AKESSON, C. Saltiness, sweetness and preference: A study of quantitative relations in individual subjects. Scandinavian Journal of Psychology, 1965, 6, 241-253.

ERNITS, T. Magnitude estimation of quinine sulfate with two methods of stimulus presentation. Unpublished undergraduate research project. Brown University, 1967.

FEALLOCK, J. B. Estimated magnitudes of taste under improved conditions of stimulus control. (Doctoral dissertation, University of Virginia) Ann Arbor: Mich: University Microfilms, 1966 , No. 66-3180.

GREGSON, R. A. M., \& RUSSELL, P. N. Psychophysical power law exponent value for sucrose intensity. Perceptual \& Motor Skilk, 1965, 20, 392.

JONES, F. N., \& MARCUS, M. J. The subject effect in judgments of subjective masnitude. Journal of Experimental Psychology, 1961, 61, 40-44.
KOCHER, E. C., \& FISHER, G. L. Subjective intensity and taste preference. Perceptual \& Motor Skills, 1969, 28 . 735-740.

LEWIS, D. R. Psychological scales of taste. Journal of Psychology, 1948, 26, 437-446.

MCBURNEY, D. H. Magnitude estimation of the taste of sodium chloride after adaptation to sodium chloride. Journal of Experimental Psychology, 1966, 72, 869-873.

McNEMAR, Q. Psychological statistics. New York: Wiley, 1962

MEISELMAN, H. L. Adaptation of cross-adpatation of the four gustatory qualities. Perception \& Psychophysics, $1968,4,368-372$

MEISELMAN, H. L. Effect of presentation procedure on taste intensity functions. Perception Psychophysics, 1971, 10, 15-18.

MEISELMAN, H. L., \& HALPERN, B. P. Effects of Gymanema syluestre on complex tastes elicited by amino acids and sucrose. Physiology \& Behavior, $1970,5,1379-1389$.

MOSKOWITZ, H. R. Scales of intensity for single and compound tastes. Unpublished doctoral thesis, Harvard University, 1968

MOSKOWTTZ, $H$, R. Sweetness and intensity of artificial sweeteners. Perception \& Psychophysics, 1970, 8, 40-42.

MOSKOWITZ, H. R. Ratio scales of acid sourness. Perception \& Psychophysics, 1971a, 9, 371-374.

MOSKOWITZ, H. R. The sweetness and pleasantness of sugars. American Journal of Psy chology, 1971b, 84, 387-405.

MOSKOWITZ, $H$. R. Perceptual changes in taste mixtures. Perception Psychophysics, 1972, 11, $257-262$.

MOSKOWITZ, H. R., \& ARABIE, $P$ Texture intensity as a function of stimulus for concentration and solvent viscosity. Journal of Texture Studies, $1970,1,501-510$

REYNOLDS, G. S., \& STEVENS, S. $s$. Binaural summation of loudness. Journal of the Acoustical Society of America. $1961,33,160-167$.

SMITH, $D$. The effect of area of stimulation on the intensity of human gustatory responses. Unpublished doctoral thesis University of Pittsburg, 1969.

STEVENS, J. C.. \& MACK, J. D. Scales of apparent force. Journal of Experimental Psychology, 1959, 58, 405-413.

STEVENS, S. S. Psychophysics of sensory function. American Scientist, 1960, 48 . 226-253.

STEVENS, S. S. Sensory scales of taste intensity. Perception \& Psychophysics, $1969,6,302-308$.

STEVENS, S. S., \& GREENBAUM, H. B Regression effect in psychophysical judgment. Perception \& Psychophysics, $1964,1,439-446$.

STEVENS, S. S., \& GUIRAO, M. Loudness reciprocality, and partition scales. Journal of the Acoustical Society of America, 1962, 34, 1466-1471.

STONE H \& OLIVER $S$. Measurement of the relative sweetness of selected sweeteners and sweetener mixtures. Journal of Food Sciences, 1969, 34 216-222.

(Accepted for publication May 30, 1972) 